\title{
Fracture modelling of composite marine T-Joint
}

\author{
H. C. H. Li* I. Herszberg $^{\dagger} \quad$ A. P. Mouritz* \\ F. Dharmawan*
}

(Received 20 March 2006; revised 28 February 2007)

\begin{abstract}
This article outlines a study on the fracture behaviour of representative 2D sections of large adhesively bonded glass fibre reinforced polymer T-joints commonly found in composite marine vessels. Finite element models of the structure were developed with various damage configurations in the adhesive bond lines which represent damage that may occur during service, particularly as a result of impact or shock loading. The T-joint sections were subjected to a straight pull-off load to simulate normal operational conditions of such structures in a ship. The fracture behaviour and damage criticality of the structure were numerically predicted using the Virtual Crack Closure Technique.
\end{abstract}

${ }^{*}$ School of Aerospace Mechanical \& Manufacturing Engineering, RMIT University, Melbourne, Australia. mailto:h.li@crc-acs.com.au

${ }^{\dagger}$ Cooperative Research Centre for Advanced Composite Structures Ltd, Melbourne, Australia.

See http://anziamj.austms.org.au/V47EMAC2005/Li for this article, (c) Austral. Mathematical Soc. 2007. Published June 26, 2007. ISSN 1446-8735 


\section{Contents}

1 Introduction

C683

2 Finite element modelling

C684

3 Horizontal disbonds

C687

4 Vertical disbonds

C691

5 Conclusion

C693

References

C693

\section{Introduction}

Fibre reinforced polymer composites have superior mechanical properties compared to traditional metallic and timber structural materials for the manufacture of marine vessels. These include high specific strength, excellent fatigue performance, and superior corrosion resistance. In order to exploit the advantages of composite materials, secondary or adhesive bonding is often necessary for the construction of structures with complex geometries. Such adhesive joints play an important role in structural load transfer. Hence, an understanding of the failure mechanisms of these joints and their load carrying capacity after sub-critical damage is important for the efficient design of these structures.

This article outlines a study on the fracture behaviour of representative 2D sections of large adhesively bonded glass fibre reinforced polymer T-joints commonly found in composite marine vessels. Finite element models of the structure were developed with various damage configurations in the adhesive bond lines which represent damage that may occur during service, particu- 


\begin{tabular}{l|ccc}
\multicolumn{4}{c}{ TABle 1: Material properties for FE models. } \\
& Hull & Overlaminate & Filler \\
\hline$E_{1}(\mathrm{GPa})$ & 26.1 & 23.5 & 3.5 \\
$E_{2}(\mathrm{GPa})$ & 3.0 & 3.0 & \\
$\nu_{12}(\mathrm{GPa})$ & 0.17 & 0.17 & 0.3 \\
$G_{12}(\mathrm{GPa})$ & 1.5 & 1.5 & 1.3
\end{tabular}

larly as a result of impact or shock loading. The T-joint sections were subjected to a straight pull-off load to simulate normal operational conditions of such structures in a ship. The Virtual Crack Closure Technique (VCCT) was used to calculate the strain energy release rates for the prediction of residual strength.

\section{$2 \quad$ Finite element modelling}

The dimensions of the T-joint are shown in Figure 1. The FE models were constructed using MSC Patran and analysed with MSC Nastran. A joint with a depth of $5 \mathrm{~mm}$ was considered and the FE models were constructed using two dimensional plain-stress shell elements, based on previous work by Dharmawan et al. [1]. Orthotropic elements were used to model the hull, bulkhead and overlaminate while isotropic elements were used for the filler. The material properties used in the models were obtained experimentally and are listed in Table 1 . The models were subjected to a one dimensional pull off load uniformly distributed at the top of the joint, which is representative of the normal operational loading of such structures. Pinned-slide boundary conditions were symmetrically applied at two nodal locations $225 \mathrm{~mm}$ from the centre (load) line on the horizontal overlaminate surface. Disbonds of various lengths were incorporated in the models at different locations of the bond lines, simulating damage which may typically occur due to impact or shock loading. The different damage configurations studied are shown in 


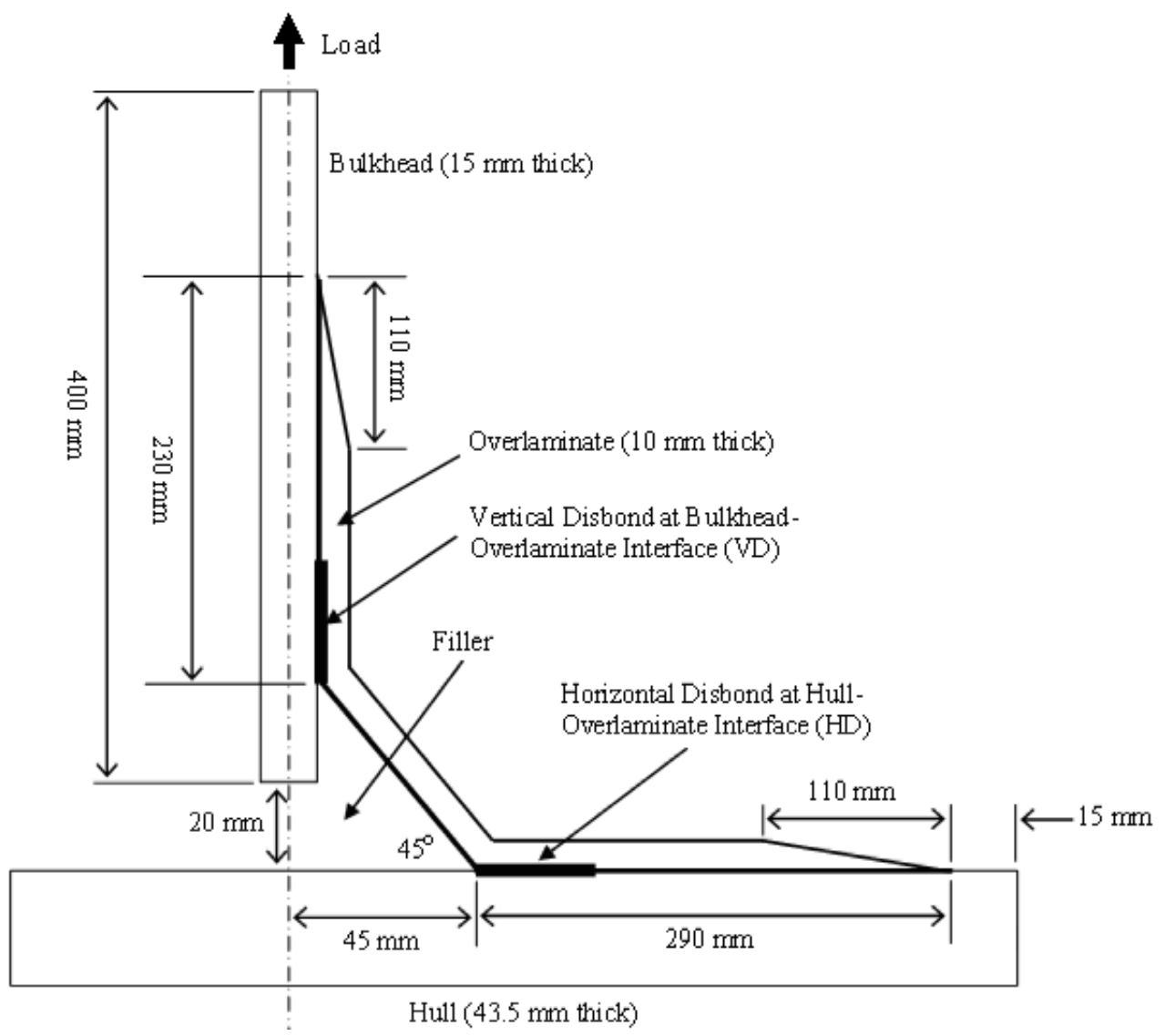

Figure 1: Dimensions of symmetrical half joint. 


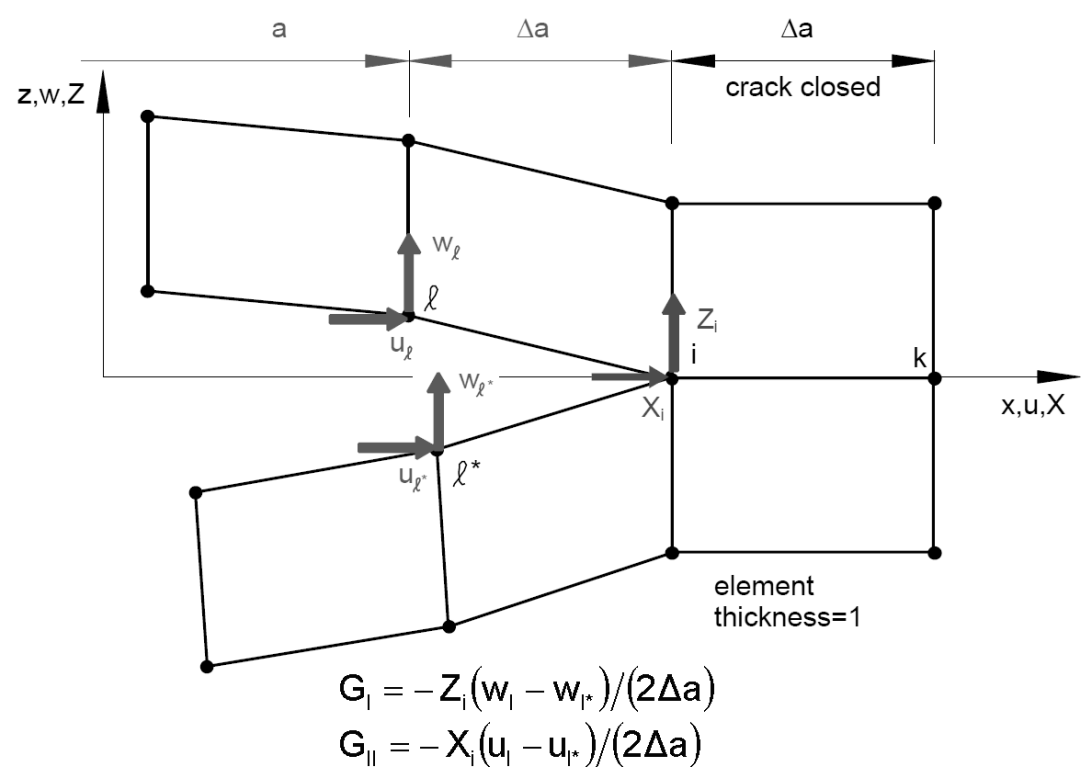

FiguRE 2: VCCT calculation scheme for four-noded quad elements [2].

Figure 1. Three disbond lengths, 30, 60 and $90 \mathrm{~mm}$ were examined at each location. The FE models were analysed using a linear static solver.

The Virtual Crack Closure Technique was used to calculate the strain energy release rates (SERR) at the tips of the disbonds at four different load steps $(6 \mathrm{kN}, 10 \mathrm{kN}, 13 \mathrm{kN}$ and $16 \mathrm{kN})$. The VCCT uses nodal forces ahead of the disbond front and displacements behind the disbond front to directly calculate the classical linear elastic fracture mechanics-based SERR components. Krueger [2] describes details of the VCCT. Figure 2 shows the calculation schemes for four-noded quad elements. In this study, the nodal forces were obtained directly by placing rigid multi-point constraints (MPC-RBAR) at the disbond tips. The ratio of the virtual crack extension to the length of the actual crack $(\Delta a / a)$ has been kept between 0.005 and 0.05 at all times. The calculated SERR values were used to predict the residual strength of the damaged T-joint using an appropriate failure criterion. 


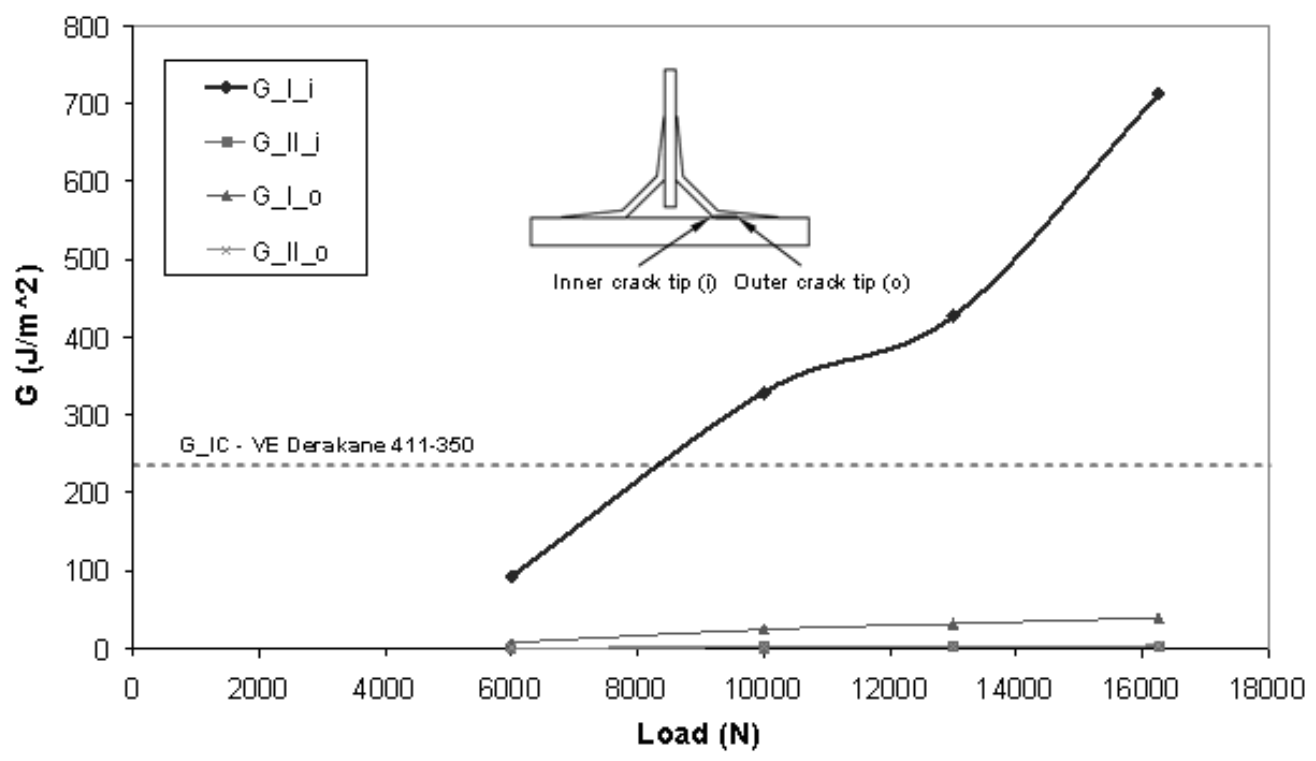

FigURE 3: SERR of T-joint with $30 \mathrm{~mm}$ initial disbond at overlaminate-hull interface.

\section{$3 \quad$ Horizontal disbonds}

The SERR versus load graph for an initial disbond size of $30 \mathrm{~mm}$ is shown in Figure 3. The SERR at the outer crack tip appears negligible compared to that at the inner crack tip, indicating that the disbond has the propensity to propagate towards the filler region only. Calculations also indicate that the SERR of the inner crack tip is dominated by the Mode I component and therefore only the Mode I fracture toughness is required for the failure criteria. At a load of approximately $8.5 \mathrm{kN}$, the Mode I SERR exceeds the fracture toughness of neat vinyl ester resin $\left(240 \mathrm{~J} / \mathrm{m}^{2}\right)$ [3], which is the principal constituent of the filler. If an assumption is made that the fracture toughness of the resin filler is less than that of the filler-hull interface (that is, the crack 
will grow within the filler rather than along the filler-hull interface), then expect that crack propagation will initiate at a load of approximately $8.5 \mathrm{kN}$.

However, the initiation of crack propagation in this case does not necessarily signify failure of the joint, because once the crack reaches the opposite filler vertex, it may be arrested due to the much greater toughness of the GFRP material into which it must grow. To investigate the likely behaviour of the disbond propagation, the initial crack length was extended in three increments until it reached the opposite filler vertex and the subsequent SERRs were calculated. The results are shown in Figure 4.

Figure 4 shows that the Mode II components of the SERRs at both crack tips remain negligible throughout the crack propagation, so that they may be ignored for the purpose of failure prediction. Figure 5a shows that the SERR of the inner crack tip possesses a negative gradient with respect to the crack length until the crack reaches the mid point of the T-joint, indicating stable crack growth (that is, a higher load is required to propagate the crack). Although only the $10 \mathrm{kN}$ load case is shown in Figure 4a, the other load cases produced similar trends. The SERR at the outer crack tip increases steadily with crack length, exceeding that at inner crack tip after a growth of approximately $20 \mathrm{~mm}$. Figure $4 \mathrm{~b}$ shows that failure at the out crack tip may be expected at a load of $12 \mathrm{kN}$ if the Mode I fracture toughness of the GFRP composite is taken to be $1500 \mathrm{~J} / \mathrm{m}^{2}$. (This higher value compared to typical Mode I fracture toughness of glass-vinyl ester composite [4] is due to the inclusion of a chopped strand mat at the bond line which is commonly used to improve joint adhesion.) The result of the analysis yields a multistage failure prediction, with the initiation of disbond propagation into the filler occurring at a load of $8.5 \mathrm{kN}$, and final failure of the outer crack tip taking place at $12 \mathrm{kN}$.

The analysis was repeated for the $60 \mathrm{~mm}$ and $90 \mathrm{~mm}$ initial disbond cases. A comparison of the two distinctive events in the failure process predicted by the VCCT for the various initial disbond sizes is shown in Figure 5. A margin exists between the disbond propagation load and the final failure load. This 


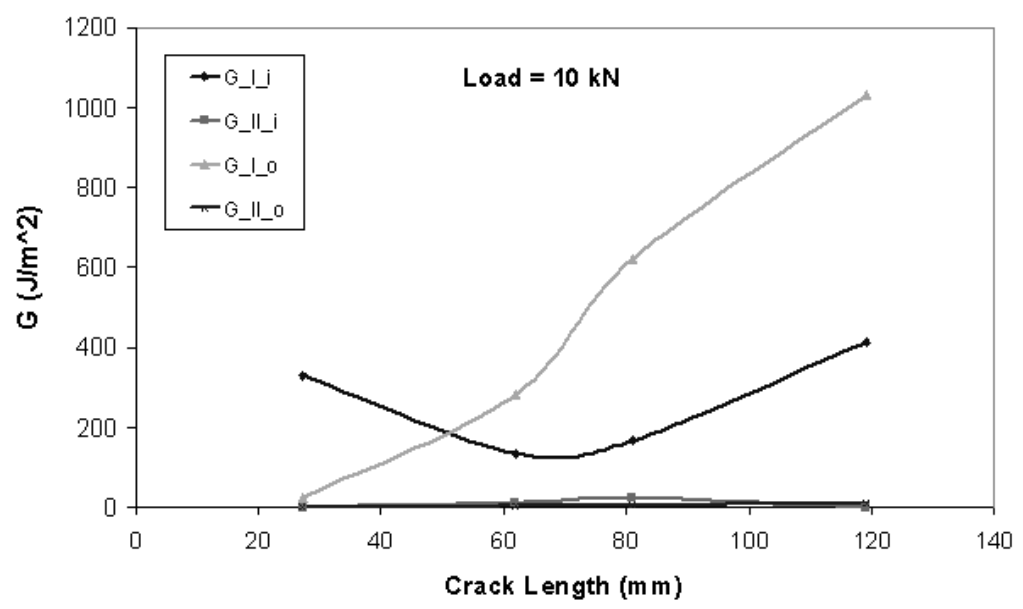

(a)

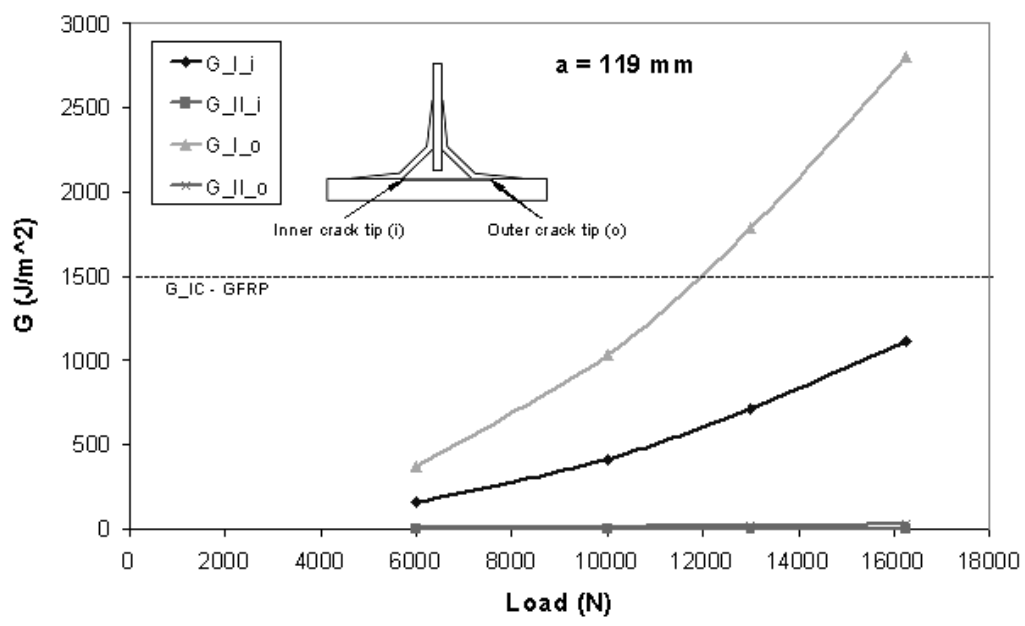

(b)

Figure 4: SERRs of T-joint with $30 \mathrm{~mm}$ initial disbond between overlaminate-hull interface: (a) SERR versus crack length; and (b) SERR versus load when disbond growth reaches other side of filler vertex. 


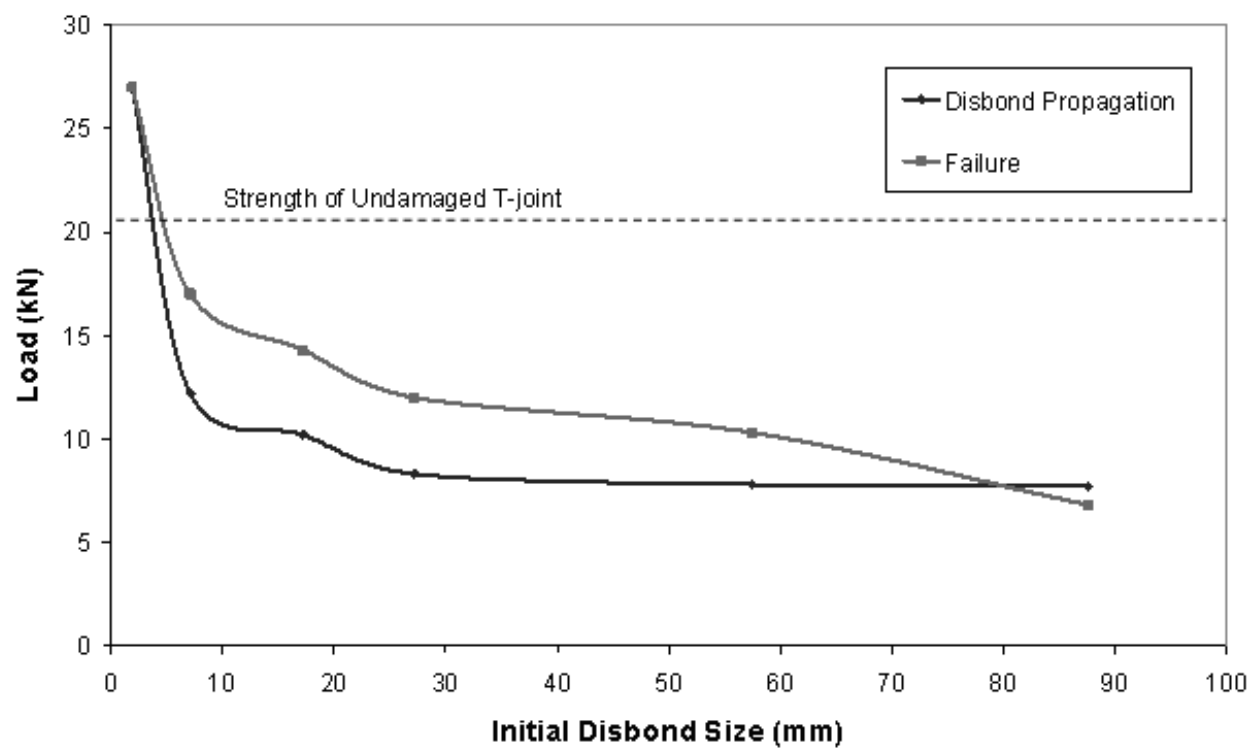

Figure 5: Failure loads for T-joints with various initial disbond sizes at horizontal overlaminate-hull interface.

margin is small for initial disbond sizes of less than $5 \mathrm{~mm}$, presumably because the minute damage has very little impact on the strength of the structure. Indeed, the predicted failure load for a T-joint with a $5 \mathrm{~mm}$ initial disbond corresponds to that of the undamaged structure measured experimentally in a previous study [5]. We infer that disbond sizes less than $5 \mathrm{~mm}$ at this location have no impact on the strength of the structure and the failure mechanism would be the same as that of the undamaged joint.

The margin becomes significant for initial disbond sizes over $10 \mathrm{~mm}$. The disbond propagation load does not decrease significantly with increasing initial disbond size of between 30 and $90 \mathrm{~mm}$. The margin between the disbond propagation load and failure load reduces steadily, reaching zero at an initial disbond size of approximately $82 \mathrm{~mm}$. The margin is negative for initial dis- 


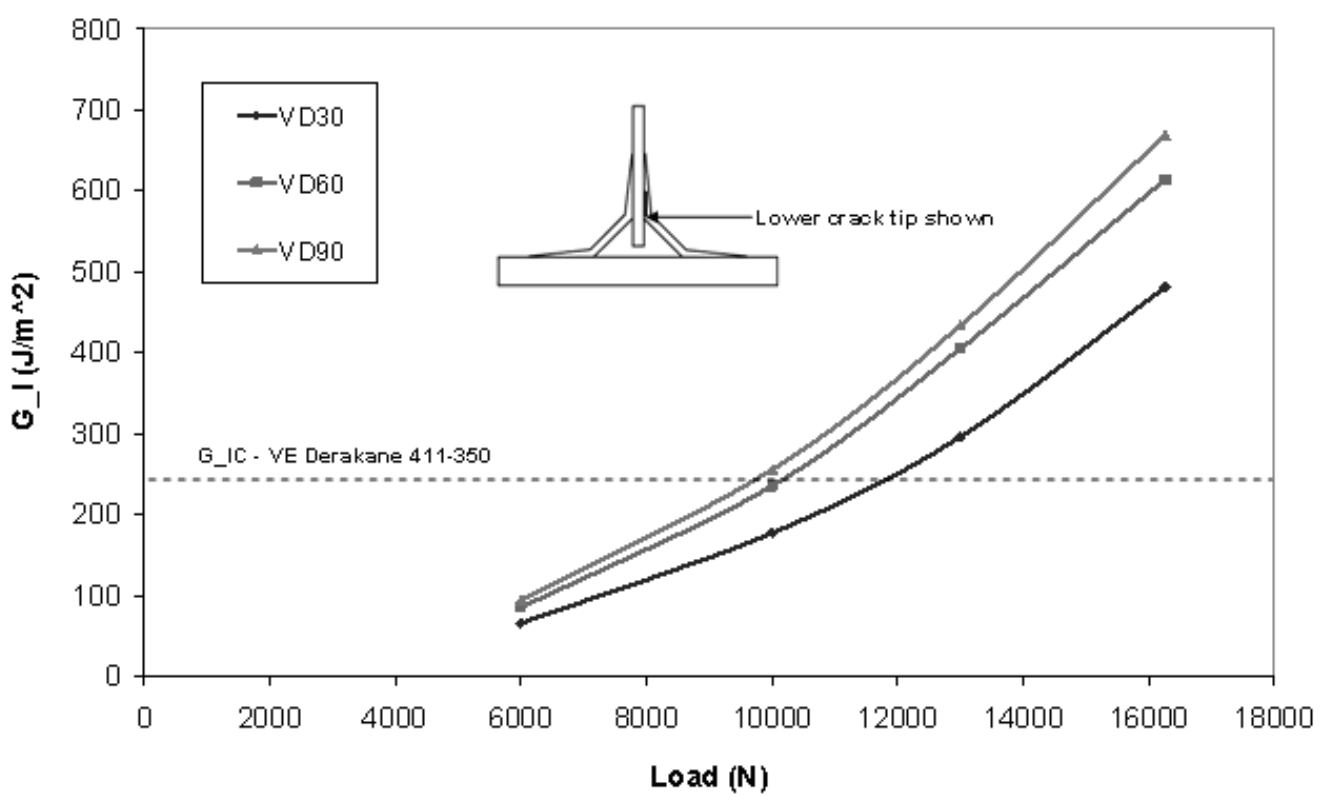

FigURE 6: SERR versus load for T-joint with initial vertical disbonds of various lengths at overlaminate-bulkhead interface.

bond sizes greater than $82 \mathrm{~mm}$, indicating that the final failure load is less than the load required to initiate disbond propagation. This information may be useful in the design of a structural health monitoring system. In this case, to ensure that the structure does not fail abruptly, the minimum detectable disbond size must be less than $80 \mathrm{~mm}$.

\section{Vertical disbonds}

The SERR graphs for the T-joint with various lengths of vertical disbonds between the overlaminate and the bulkhead are shown in Figure 6. Only those 


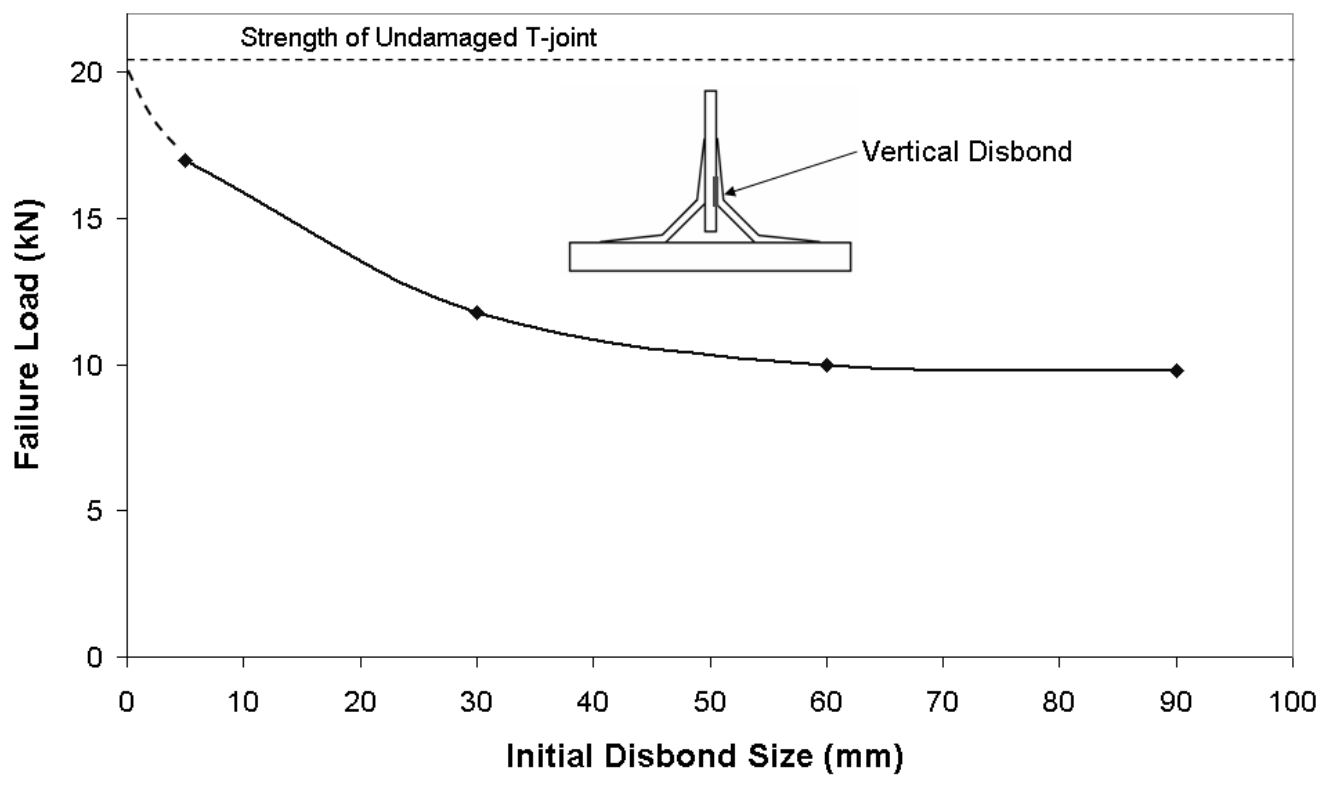

Figure 7: Failure loads for T-joints with various initial disbond sizes at vertical overlaminate-bulkhead interface.

for the lower disbond tip are shown because the SERR at the upper disbond tip in all cases was non-critical in relation to the fracture toughness of the GFRP composite, even at the highest load step. In contrast, the lower disbond tip extends into the filler region, which has a much lower fracture toughness compared to the GFRP composite. Hence, expect that disbond propagation occurs at the lower crack tip preferentially. FE modelling conducted in an earlier study showed that once the crack reached the hull, it would quickly spread horizontally due to the creation of severe stress concentrations [6]. Therefore, failure can be considered upon the initiation of crack propagation into the filler.

The Mode II components of the SERRs were found to be negligible and omitted in Figure 6. This also allows the Mode I fracture toughness of 
the resin to be used alone for the failure criterion. Figure 6 shows that the predicted failure load for the T-joint with a $30 \mathrm{~mm}$ vertical disbond is $11.8 \mathrm{kN}$. When the initial disbond length is increased to $60 \mathrm{~mm}$, the predicted failure load decreases to $10 \mathrm{kN}$. Increasing the initial disbond length further appears to have a diminishing effect, with the predicted failure load reaching $9.8 \mathrm{kN}$ for an initial disbond of $90 \mathrm{~mm}$.

A comparison of the failure load against the initial disbond size is shown in Figure 7: if the curve is extrapolated as shown by the dotted line, the predicted failure load of the undamaged structure corresponds well to the experimental result. This indicates that the vertical bond line is a critical region where even a small disbond can significantly degrade the strength of the structure.

\section{Conclusion}

A finite element study has been conducted, using the virtual crack closure technique, to investigate the fracture behaviour of marine GFRP composite Tjoint. T-joints with various damage locations and sizes have been considered and the strain energy release rates at the tips of the disbonds under a pull-off load were calculated to predict the mechanisms and loads of failure. It has been demonstrated that the Virtual Crack Closure Technique successfully models the fracture behaviour of composite marine T-joints.

\section{References}

[1] F. Dharmawan, R. S. Thomson, H. C. H. Li, I. Herszberg and E. Gellert. Geometry and Damage Effects in a Composite Marine T-Joint, Composite Structures, 66, 2004, 181-187. C684 
[2] R. Krueger. The Virtual Crack Closure Technique: History, Approach and Applications, NASA/CR-2002-211628, 2002. C686

[3] J. J. La Scala, J. A. Orlicki, C. Winston, E. J. Robinette, J. M. Sands and G. R. Palmese. The use of Bimodal Blends of Vinyl Ester Monomers to Improve Resin Processing and Toughen Polymer Properties, Polymer, 46, 2005, 2908-2921. C687

[4] P. Suppakul and S. Bandyopadhyay. The Effect of Weave Pattern on the Mode-I Interlaminar Fracture Energy of E-Glass/Vinyl Ester Composites, Composites Science and Technology, 62, 2002, 709-717. C688

[5] H. C. H. Li, I. Herszberg, C. E. Davis and A. P. Mouritz. Disbond Detection in Bonded Composite Ship Joints Using Embedded Bragg Grating Sensors, in Proceedings of the 2nd Australasian Workshop on Structural health Monitoring, Melbourne, Australia, 2004. C690

[6] H. C. H. Li, I. Herszberg and A. P. Mouritz. Strain Distributions Due to Disbonds in Composite Ship Joints, in Proceedings of the 4th Australasian Congress on Applied Mechanics, Melbourne, Australia, 16-18 February, 2005. C692 